\title{
Determinants of Health Care Utilization among the Elderly Popu- lation in Jimma Town, Oromia Region, Southwest Ethiopia
}

\author{
Yonas Biratu Terfa*, Gugsa Nemera Germossa, Fikadu Balcha Hailu, Garumma Tolu \\ Feyissa, Fikru Tafese Jaleta and Shimeles Ololo Sinkie \\ Faculty of Health Sciences, School of Nursing and Midwifery, Institute of Health Science, Jimma University, \\ Ethiopia
}

*Corresponding author: Yonas Biratu Terfa, Faculty of Health Sciences, School of Nursing and Midwifery, Institute of Health Science, Jimma University, Jimma Town, Ethiopia, P.O.B/Postal 378, Tel: +251-913-826-248

\begin{abstract}
Aim: To assess determinants of health care utilization among the elderly population in Jimma town, Oromia region, southwest Ethiopia, 2012.

Methods: A community-based cross-sectional study on 422 residents was conducted in Jimma town, from November 1-8, 2012. Respondents were identified using multistage sampling methods. Data was collected using face to face interviewer. The data was entered into Epi Data version 3.1 and exported to Statistical Package for Social Sciences version 20. Logistic regression analysis was carried out and all variables with p-value less than 0.25 in the bivariate analysis were candidates for multivariable logistic regression analysis to identify a variable which has a significant association.
\end{abstract}

Results: Among a total of 422 study subjects planned 417 gave their complete responses. Nearly two-thirds of the respondents have utilized a modern health care facility in the last three years. General checkup - $43.2 \%$ and hospital admission \& treatment $-20.8 \%$ were the major reason for the visit to the health care facility. The burden of illness (95\% Cl of 8.00-50.00) and Physical and mental health status $(95 \% \mathrm{Cl}$ of $8.1-25.5)$ are the main determinants of health service utilization among elderly in Jimma town.

Concussion: Burden of illness Physical and mental health status are the major the main determinants of health service utilization among elderly in Jimma town.

\section{Keywords}

Care, Elderly, Jimma town

\section{Introduction}

Aging is the normal process of time-related change, begins with birth and continues through life [1]. Aging Population is one of the most important demographic events in the $21^{\text {st }}$ century. According to the UN, elderly people are those people whose age is 60 years and above [2]. This also corresponds with Ethiopia's official retirement age [3].

Globally, the number of older persons is growing faster than the numbers of people in any other age group. As a result, the share of older persons in the total population is increasing virtually everywhere. In 2017, there are an estimated 962 million people aged 60 or over in the world, comprising 13 percent of the global population. The number of older persons in the world is projected to be 1.4 billion in 2030 and 2.1 billion in 2050 and could rise to 3.1 billion in 2100, in Ethiopia an older people (> 60 years) represent $5 \%$ of the total population [4]. In Oromia, according to 2007 census report the total elderly population is estimated to be 854,673 [5].

This increase consequently creates a growing pressure on the public health care delivery system and provision of health care services for older people is different across countries, continents and cultural societies. In developed regions of the world, health care is often provided by well-equipped public health facilities and nursing homes designated for elderly individuals. In most Sub-Saharan African countries, availability and utili- 
zation of health care services among the elderly are being poorly reported. as people age, they become more vulnerable to ill-health. More dependent, likely to develop chronic diseases, and expend more to the health care $[6,7]$.

An individual's decision to utilize health care services is a result of a complex interaction of factors relating to the person's health self-perceived health status, and the availability of the health care services on offer [8]. The determinants of health service utilization among the elderly can be grouped into three broad categories according to Wan and Odell using the Andersen behavioral model [9]. These are personal attributes which may predispose individuals to seek care; need for care as evidenced by both subjective (perceived or self-reported) health status and objective (assessed by a physician) health status; and enabling factors such as financial capability to pay for care, ability to get to places where services are offered, and knowledge about the services available. The predisposing factors include social, structural and demographic factors which influence health care attitudes and beliefs. Need for care factors include poor or ill health, chronic conditions, and limited physical activity performance. Need for health care is usually measured by symptoms of illness perceived by the individual, their responses and medical assessment of the condition by the physician $[8,9]$.

Researchers have shown an increased interest in studying factors which determine the utilization of health services. This is generally meant to identify cultural, social, psychological and economic factors that affect variation in the utilization of health services. Generally, the explanatory variables have been found to be personal attributes which may predispose individuals to seek care, need for services as evidenced by illness and enabling factors such as financial capability to pay for care, ability to get to places where services are offered, and knowledge about the service network in the community [5].

Population-based studies in developed countries have shown that predictive characteristics for hospital admissions in the ageing population include variables such as poor self-perceived health status, more advanced age, greater number of visits to a doctor in the previous year, greater number of medications utilized, inability to perform some activities of daily living (ADL) and presence of certain diseases, such as coronary heart disease and diabetes $[5,6,10]$. However, to the best of our knowledge, there is paucity of information on study conducted on the determinants of elderly health care utilization in Oromia in general and in Jimma town in particular. Thus, this is noteworthy to evidently identify determinants of health care utilization among the elderly population in the context of Jimma town, Oromia region, southwest Ethiopia.

\section{Methods and Materials}

\section{Study design and settings}

Community-based cross-sectional survey was conducted on randomly selected elderly people living in Jimma town from November 1-8, 2012. Jimma is located $357 \mathrm{~km}$ south west from the capital city of Ethiopia, Addis Ababa. The town has a total of 128 health institution; one referral hospital, one governmental and one private hospital, 4 health centers, 55 private clinics, 25 pharmacies, 36 drug stores, and 5 drug distributors. Elderly people aged 65 and above years and who have been residing for more than a year in of Jimma Town was included in the study and those who critically ill to communicate was excluded.

\section{Sample size and sampling techniques}

The Sample for this study was determined using sample size formula for estimating a single population proportion with a margin of error of $5 \%$, confidence interval of $95 \%$, proportion $50 \%$ and expected non-response rate of $10 \%$. Based on information obtained from Jimma town administrative office total numbers of the elderly population in the respective kebeles (lowest administrative unit) are identified and proportionally allocated to sample size. The sampling frame was developed using records from kebele administration and urban health extension services. Finally, simple random sampling was employed to select the study subjects.

\section{Study variables}

Modern Health service utilization is the outcome variable whereas; Age, Sex, Educational status, Marital status, Family size, Presence of children \& grandchildren, Use of substances (tobacco, alcohol, and Khat) were Predisposing factors; Occupation, Monthly Income, Source of income, Living arrangements, Working distance from the health institution was Enabling factor; and Self-reported health status, medical history of chronic conditions (stroke, arthritis, diabetes, angina, chronic lung disease, asthma, depression, hypertension, cataracts), Cognitive impairment (i.e. difficulty with concentrating or remembering things in the last 30 days), Difficulty with picking up things in the last 30 days, Functional status in performing ADL and self-care were Need factor.

In this study Modern Health service utilization refers to the visit of an elderly person to public, private or NGO hospital, health center, clinic, or health post for seeking promotive, preventive, curative, or rehabilitative service at least once in a year; or a health care service given by health extension workers with full request/willingness of the elderly.

\section{Data collection instrument and procedures}

Data collection tools were adapted after reviewing of relevant the literature and the instrument includes 
both closed and open-ended questionnaires.

\section{Data process and analysis}

After checking completeness data was entered using Epi Data version 3.1 and exported to SPSS version 20 for analysis. Descriptive statistics was employed to see distribution of the variables. Binary Logistic regression analysis was carried out and all variables with $p$-value less than 0.25 in bi-variate analysis was considered as candidates for multiple logistic regression analysis to identify a variable which have significant association based on OR, with $95 \% \mathrm{Cl}$ and $\mathrm{P}$ value of less than 0.05 .

\section{Ethical considerations}

Ethical clearance was obtained from Institutional Review board of Jimma University. A formal letter from Institute of health science was submitted to Jimma town municipality to obtain their cooperation. Ethical issues within the study was taken into consideration when carrying out the study at the initial stage of data collection and interview informed consent was taken from respondents and the participants was assured that their participation was recorded anonymously.

\section{Results}

\section{Predisposing factor}

Among a total of 422 study subjects planned, 417 gave their responses which give a response rate of $98.8 \%$. Majority of the respondents (85.9\%) were in age group 60-79 years, just over half (51.6\%) were female and nearly half (51.6\%) of them were never been involved to formal school and $60 \%$ had ever used substance (Table 1).

Table 1: Elderly health care utilization predisposing factor, Jimma town, Oromia, Southwest Ethiopia, 2012.

\begin{tabular}{|c|c|c|c|}
\hline \multicolumn{2}{|c|}{ Predisposing Factors } & \multirow{2}{*}{$\begin{array}{l}\text { Frequency } \\
\text { (n = 417) }\end{array}$} & \multirow{2}{*}{\begin{tabular}{|l|}
$\%$ \\
85.9 \\
\end{tabular}} \\
\hline \multirow[t]{3}{*}{ Age } & $60-79$ years & & \\
\hline & $\geq 80$ years & 59 & 14.1 \\
\hline & \multicolumn{2}{|c|}{ Mean \pm SD $71.2 \pm 7.2$ years } & \\
\hline \multirow[t]{2}{*}{ Sex } & Male & 202 & 48.4 \\
\hline & Female & 215 & 51.6 \\
\hline \multirow[t]{4}{*}{ Marital status } & Never married & 14 & 3.4 \\
\hline & Married & 194 & 46.5 \\
\hline & Divorce & 50 & 12.0 \\
\hline & Widowed & 159 & 38.1 \\
\hline \multirow{2}{*}{$\begin{array}{l}\text { Ever been to } \\
\text { formal school }\end{array}$} & Yes & 202 & 48.4 \\
\hline & No & 215 & 51.6 \\
\hline \multirow{2}{*}{$\begin{array}{l}\text { Ever used } \\
\text { substances }\end{array}$} & Yes & 250 & 60.0 \\
\hline & No & 167 & 40.0 \\
\hline \multirow{3}{*}{$\begin{array}{l}\text { Types of } \\
\text { substance used } \\
(n=250)\end{array}$} & Khat & 109 & 43.6 \\
\hline & Tobacco & 16 & 6.4 \\
\hline & Alcohol & 125 & 50.0 \\
\hline
\end{tabular}

\section{Enabling factor}

Half $(49.6 \%)$ of the respondents were live in rented house, most $(85.6 \%)$ the respondents didn't have enough money to meet their needs, and about (46\%) never had occupation. Regarding their Living arrangements about one third them lives alone. Two-third of the respondents were unable to pay for medical service, $59 \%$ of them can able reach health facility within 30 minutes and only one sixth of them had monthly income $\geq 750$ Ethiopian birr (Table 2).

Table 2: Elderly health care utilization Enabling factor, Jimma Town, Oromia, Southwest Ethiopia, 2012.

\begin{tabular}{|c|c|c|c|}
\hline \multicolumn{2}{|l|}{ Enabling Factor } & \multirow{2}{*}{$\begin{array}{l}\text { Frequency } \\
(n=417) \\
207\end{array}$} & \multirow{2}{*}{$\begin{array}{l}\% \\
49.6\end{array}$} \\
\hline \multirow[t]{3}{*}{ Home } & Own & & \\
\hline & Private rent & 78 & 18.7 \\
\hline & Municipal rent & 132 & 31.7 \\
\hline \multirow{2}{*}{$\begin{array}{l}\text { Money to meet } \\
\text { needs }\end{array}$} & Enough & 60 & 14.4 \\
\hline & Not enough & 357 & 85.6 \\
\hline \multirow{7}{*}{$\begin{array}{l}\text { Ever had } \\
\text { occupation }\end{array}$} & No & 192 & 46.0 \\
\hline & Gov't employee & 58 & 13.9 \\
\hline & Self employed & 94 & 22.5 \\
\hline & Farmer & 24 & 5.8 \\
\hline & Merchant & 24 & 5.8 \\
\hline & Daily laborer & 12 & 2.9 \\
\hline & Other & 13 & 3.1 \\
\hline \multirow{6}{*}{$\begin{array}{l}\text { Living } \\
\text { arrangements }\end{array}$} & Living alone & 123 & 29.5 \\
\hline & Family & 99 & 23.7 \\
\hline & Partner & 114 & 27.3 \\
\hline & Relative & 52 & 12.5 \\
\hline & Daughter or son & 18 & 4.3 \\
\hline & Servant & 11 & 2.6 \\
\hline \multirow[t]{4}{*}{ Family support } & Low & 99 & 23.7 \\
\hline & Moderate & 111 & 26.6 \\
\hline & High & 38 & 9.1 \\
\hline & None & 169 & 40.5 \\
\hline \multirow{5}{*}{$\begin{array}{l}\text { Who gives care } \\
\text { for during illness }\end{array}$} & No & 80 & 19.2 \\
\hline & Spouse & 105 & 25.2 \\
\hline & Child & 205 & 49.2 \\
\hline & Servant & 25 & 6.0 \\
\hline & Other & 2 & 0.5 \\
\hline \multirow{2}{*}{$\begin{array}{l}\text { Being able to } \\
\text { afford food }\end{array}$} & Yes & 256 & 61.4 \\
\hline & No & 161 & 38.6 \\
\hline \multirow{2}{*}{$\begin{array}{l}\text { Being able to } \\
\text { pay for medical } \\
\text { service }\end{array}$} & Yes & 137 & 32.9 \\
\hline & No & 280 & 67.1 \\
\hline \multirow{3}{*}{$\begin{array}{l}\text { Distance from } \\
\text { a nearby health } \\
\text { facility }\end{array}$} & Within 30 minutes & 246 & 59.0 \\
\hline & $30-60$ minutes & 162 & 38.8 \\
\hline & $>60$ minutes & 9 & 2.2 \\
\hline \multirow[t]{2}{*}{ Monthly income } & $<750$ birrs & 355 & 85.1 \\
\hline & $\geq 750$ birrs & 62 & 14.9 \\
\hline
\end{tabular}


Table 3: Elderly health status, and medical history of chronic conditions, Oromia, Jimma Town, 2012.

\begin{tabular}{|c|c|c|c|}
\hline \multicolumn{2}{|l|}{ Self-reported health status } & Frequency $(n=417)$ & $\%$ \\
\hline \multirow{5}{*}{$\begin{array}{l}\text { Physical and mental health status rating during the last } 30 \\
\text { days }\end{array}$} & Very bad & 12 & 2.9 \\
\hline & Bad & 47 & 11.3 \\
\hline & Moderate & 272 & 65.2 \\
\hline & High & 78 & 18.7 \\
\hline & Very high & 8 & 1.9 \\
\hline \multirow[t]{2}{*}{ Difficulty with picking up things in the last 30 days } & Yes & 112 & 26.9 \\
\hline & No & 305 & 73.1 \\
\hline \multirow{2}{*}{$\begin{array}{l}\text { Difficulty seeing and recognizing an object at a distance of } \\
\text { about } 20 \text { meters }\end{array}$} & Yes & 115 & 27.6 \\
\hline & No & 302 & 72.4 \\
\hline \multirow[t]{2}{*}{ Cognitive impairment in the last 30 days } & Yes & 97 & 23.3 \\
\hline & No & 320 & 76.7 \\
\hline \multirow[t]{3}{*}{ Feels pain } & Always & 33 & 7.9 \\
\hline & Sometimes & 259 & 62.1 \\
\hline & Never & 125 & 30.0 \\
\hline
\end{tabular}

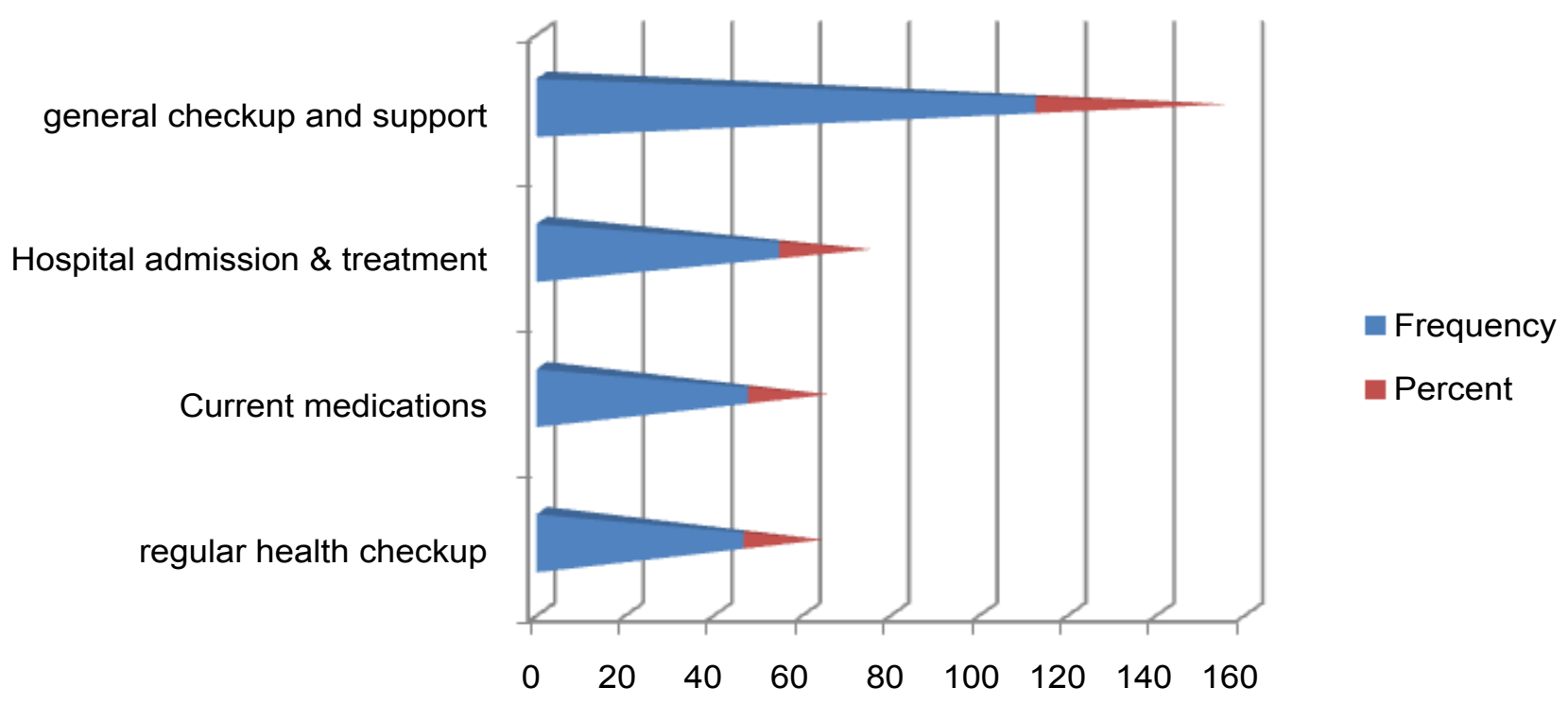

Figure 1: Reason for elderly health service utilization, Jimma Town, Oromia region, South West Ethiopia, 2012.

\section{Need factor}

Nearly two thirds (65.2\%) of the respondents had moderate physical and mental during the last 30 days, just over one-fourth (26.9\%) reported difficulty with picking up things in the last 30 days $27.6 \%$ had difficulty of seeing and recognizing an object at a distance of about 20 meters, about one forth (23.3\%), had history of cognitive impairment in the last 30 days and $62.1 \%$ feels pain sometimes (Table 3 ).

\section{Health service utilization}

Nearly two third of the respondents (62.1\%) had utilized modern health care facility in the last three years. General checkup and hospital admission \& treatment were reported as major reason for visit health care facility (Figure 1).

\section{Determinants of health service utilization}

Burden of illness and, Physical and/or mental health status in the past 30 days are the main determinants health service utilization among elderly in Jimma town. Elderly people those who had two or more morbidity has 20 times more likely to utilize modern health facility (95\% Cl of 8.00-50.00) where as those who had single morbidity were 14 times more likely to utilize modern health care facility ( $95 \% \mathrm{Cl}$ of $8.1-25.5)$ when compared to those who did not reported have illness. Elderly people who reported bad physical and mental health status in the past 30 days were almost six times more likely to utilize modern health care facility $(95 \% \mathrm{Cl}$ of $2.2-$ 8) (Table 4).

\section{Discussion}

This study aimed to assess determinants of health care utilization among the elderly population in Jimma town. The findings indicates, nearly two third elderly 
Table 4: Logistic regression analysis of factors associated with Elderly modern health care utilization health in Oromia, Jimma Town, 2012.

\begin{tabular}{|l|l|l|l|l|}
\hline \multicolumn{2}{|l|}{ Factors } & \multicolumn{2}{l|}{ Utilization } & AOR (95\% 95\% CI)/P.V \\
\cline { 2 - 5 } & & Not & Utilized & \\
\hline \multirow{2}{*}{ Burden of illness } & Single case & 21 & 140 & $14.3(8.1-25.5) / 0.00$ \\
\cline { 2 - 5 } & Double or more morbidity & 6 & 65 & $20(8.00-50.00) / 0.00$ \\
\hline & No morbidity & 131 & 54 & 1 \\
\hline $\begin{array}{l}\text { Physical and mental health status } \\
\text { in the past 30 days }\end{array}$ & Bad & 11 & 48 & $5.7(2.2-15) / 0.000$ \\
\cline { 2 - 5 } & Moderate & 85 & 187 & $4.1(2.2-8) / 0.000$ \\
\hline & High & 62 & 24 & 1 \\
\hline
\end{tabular}

people in the town utilize modern health care services when they had a number of co-morbidity and poor physical and/or mental health status. General checkup and hospital admission \& treatment were reported as major reason for visit to the health care facility. This is similar with study conducted in the Nepal, and Taiwan $[11,12]$, However, better than study conducted in the Rural Part of Wolaita Zone, Southern Ethiopia (57.9\%), in Bedele Town, Illubabor Zone, West Ethiopia (49.6\%) $[13,14]$. The discrepancy in these findings may be due to the differences in the place of residency in which the current study is conducted in urban area while previous studies are conducted in rural areas. Thus, distance from health facility, and lack of access to information may put people in urban residency at better advantage. Concerning the medical history of chronic condition, this study showed that, more than half $(55.6 \%)$ of the respondents were Suffering from in one or more of chronic illness such as arthritis, hypertension, and cataract. this is comparable with reports from Bedele Town, Illubabor Zone [14].

In the present study Burden of illness and Physical and/or mental health status in the past 30 days are the main determinants health service utilization among elderly in Jimma town. Elderly people those who had double or more morbidity has 20 times more likely to utilize modern health facility than those who do not have illness [95\% Cl = 20 (8.00-50.00)]. Elderly people who reported bad physical and mental health status in the past 30 days were almost six times more likely to utilize modern health care facility than those who reported high physical and mental health status $[95 \% \mathrm{Cl}=5.7$ $(2.2-15)]$. This is consistent with study conducted in Bedele Town, Illubabor Zone, Ethiopia which Respondents with a medical history of at least one chronic condition 1.737 times utilize health care than participants without any of the chronic conditions [14].

In contrary to this conducted in Nepal, Malaysia and Ethiopia showed that; Age, marital status, educational status, income level, activities of daily living, and regular medication were significantly associates with health services utilization $[11,13,15]$. The difference may due to time of data collection, place of residency and economic status. As we know education is the key for any things in our daily life therefore expansion of school and empowering adults learning is very important to maintain the health of elderly people and to increasing the elderly utilization of health care services. Since accessibility of to the health facility are the determinant for appropriate health care seeking behavior of elderly people, expansion of elderly friendly health facility, should be augmented.

\section{Consent to Publish}

The University allowed us to publish this paper and all authors who participated in this study are listed under authors and they agree for the publication process.

\section{Competing Interest}

There is no competing of interest among us and with other bodies.

\section{Funding}

Jimma University staff research support program.

\section{Acknowledgements}

We thanks to Jimma University, Institute of Health, Faculty of Health Sciences and School of Nursing and Midwifery for provide us basic ground work to do this research. Our sincere and deepest gratitude goes to Jimma town municipality office for their willingness to give all important information needed for this research. Lastly but not the least we would like to appreciate study subjects and anyone who involved due process of this paper.

\section{References}

1. Suzanne C O'Connell Smeltzer, Brenda G Bare (2004) Brunner and Suddarth's textbook of medical-surgical nursing. ( $10^{\text {th }}$ edn), Lippincott Williams and Wilkins, 188.

2. Health statistics and information systems. World Health Organization.

3. Ministry of Labor and Social Affairs (2012) National social protection policy of Ethiopia.

4. Department of Economic and Social Affairs (2017) Population division world population prospects: The 2017 revision - Key findings and advance tables. United Nations, New York.

5. Central Statistical Authority (2007) Ethiopian population and housing census. Addis Ababa, Ethiopia.

6. Jamison DT, Mosley WH (1991) Disease control priorities 
in developing countries: Health policy responses to epidemiological change. Am J Public Health 81: 15-22.

7. Palangkaraya A, Yong J (2009) Population ageing and its implications on aggregate health care demand: Empirical evidence from 22 OECD countries. Int $\mathrm{J}$ Health Care Finance Econ 9: 391-402.

8. Fernández-Olano C, Hidalgo JD, Cerdá-Díaz R, RequenaGallego M, Sánchez-Castaòo C, et al. (2006) Factors associated with health care utilization by the elderly in a public health care system. Health Policy 75: 131-139.

9. Aday LA, Andersen R (1974) A framework for the study of access to medical care. Health Serv Res 9: 208-220.

10. Borges-Yañes AS, Gomes-Dantes H (1998) Uso de los servicios de salud por la población de 60 años y más en México. Salud Pública de México 40: 1-11.

11. Sanjel S, Mudbhari N, Risal A, Khanal K (2012) The utilization of health care services and their determinants among the elderly population of Dhulikhel municipality. Kathmandu Univ Med J (KUMJ) 10: 34-39.

12. Chang WC, Lan TH, Ho WC, Lan TY (2010) Factors affecting the use of health examinations by the elderly in Taiwan. Arch Gerontol Geriatr 50: S11-S16.

13. Falaha T, Worku A, Meskele M, Wolde Facha (2016) Health Care seeking behaviour of elderly people in rural part of Wolaita Zone, Southern Ethiopia. Health Sci J 10: 4.

14. Amente T, Kebede B (2016) Determinants of health service utilization among older adults in Bedele Town, Illubabor Zone, Ethiopia. J Diabetes Metab 7: 713.

15. Noor'ain Mohamad Yunus, Noor Hazilah Abd Manaf, Azura Omar, Nurita Juhdi, Mohd Azahadi Omar, et al. (2017) Determinants of healthcare utilisation among the elderly in Malaysia. Institutions and Economies 9: 115-140. 